Intersections

Canadian Journal of Music

Revue canadienne de musique
Intersections CANADAN TOURAAL OP NUST

\title{
Samba : entre musique, danse et carnaval
}

\section{Grégoire Niehaus}

Volume 29, numéro 2, 2009

URI : https://id.erudit.org/iderudit/1000042ar

DOI : https://doi.org/10.7202/1000042ar

Aller au sommaire du numéro

\section{Éditeur(s)}

Canadian University Music Society / Société de musique des universités canadiennes

ISSN

1911-0146 (imprimé)

1918-512X (numérique)

Découvrir la revue

Citer cet article

Niehaus, G. (2009). Samba : entre musique, danse et carnaval. Intersections, 29(2), 109-114. https://doi.org/10.7202/1000042ar
Résumé de l'article

À travers une perspective historique, il s'agit de synthétiser les théories relatives à l'une des musiques et des danses les plus représentatives de la culture brésilienne : la samba. Nous y trouverons des réflexions sur l'un de ses mythes d'origine ainsi que sur la création des écoles de samba et leur imbrication progressive dans le carnaval et dans le coeur du Brésil.
All Rights Reserved (C Canadian University Music Society / Société de musique des universités canadiennes, 2010
Ce document est protégé par la loi sur le droit d'auteur. L'utilisation des services d'Érudit (y compris la reproduction) est assujettie à sa politique d'utilisation que vous pouvez consulter en ligne.

https://apropos.erudit.org/fr/usagers/politique-dutilisation/ 


\section{SAMBA : ENTRE MUSIQUE, DANSE ET CARNAVAL}

\section{Grégoire Niehaus}

D’une manière générale, la musique occupe une place importante dans la culture brésilienne. Selon Antonio Hohlfeldt ${ }^{1}$, elle est « un rapport au mélange culturel. Elle englobe la culture portugaise, indienne et noire. Les Portugais ont amené la musique classique, l'opéra ; les Indiens ont, pour leur part, amené les rythmes, et ce que l'on qualifie communément de « musique primitive »; enfin, les Noirs ont amené la samba et la musique des champs, comme l'ont fait leurs homologues en Amérique du Nord dans les champs de coton. La musique est toujours présente au Brésil ».

Cet article propose une synthèse des éléments de connaissance que nous possédons de la culture brésilienne, plus particulièrement de la samba, alors envisagée dans une perspective historique.

\section{LA MUSIQUE SAMBA}

Si nous considérons que l'histoire contemporaine de la samba débute à l'aube $\mathrm{du} \mathrm{XX}^{\mathrm{e}}$ siècle, nous pouvons dire qu'à ses origines, elle était une musique basée sur l'improvisation, pratiquée par les esclaves africains dans les colonies brésiliennes. Gardons cependant à l'esprit, comme l'indique Chris McGowan, qu'« une définition froide et technique ne saurait exprimer ce qu'est la samba et tout l'univers qui l'entoure » (McGowan et Pessanha 1999, p. 27). En 1917 va s'opérer l'un de ses plus grands tournants avec l'enregistrement sur disque de Pelo telefone ${ }^{2}$ écrit par Donga, «qui fut l'un des premiers compositeurs de samba à faire une tournée en Europe » (Guillermoprieto 1992, p. 36). Avec l'introduction au Brésil en 1900 de gramophones que seuls les colons possédaient, la samba put étendre sa cote de popularité auprès de cette classe sociale qui en tomba littéralement amoureuse. Les Noirs la pratiquaient dans les rues et les Blancs faisaient de même dans leurs salons. Toutes les catégories sociales étaient touchées par ce phénomène. Avec le disque, l'improvisation, qui était la notion première de la samba originelle, disparaît en emportant avec elle le folklore lié à la samba-de-roda.

Ce dernier terme mérite quelques explications. "Les prémices exactes de l'évolution de la samba restent inconnues mais on ne manque pas d'hypothèses à propos de ses origines " (McGowan et Pessanha 1999, p. 28). La plus répandue fait référence à l'umbiganda. Ce terme était employé pour désigner une danse

1 Antonio Hohlfeldt est professeur de communication à l'Université Catholique de Rio Grande do Sul (Brésil). Ces propos ont été recueillis lors d'un entretien passé à Montpellier le 29/01/2009.

2 Premier morceau de samba commercialisé. 
que pratiquaient les esclaves africains, et fonde l'une des origines probable de la samba actuelle. Il signifie « le 'coup de nombril' par lequel le soliste au centre de la roda, passait le relai à un autre " (Galvão 2000, p. 193). L'improvisation était alors sa plus grande qualité, que ce soit dans le domaine de la danse ou de la musique. L’umbiganda était fortement réprimée, au même titre que d'autres marques de la culture africaine que les Portugais cherchaient à maîtriser au sein de leurs colonies. "Les activités musicales, exercées à l'origine par des Noirs anciens esclaves puis par leurs descendants, ont été réprimées par la police dès l'époque coloniale, qu'elles soient profanes comme la samba-de-roda et la batuque ou religieuses comme les rituels du candomblé » (Galvão 2005, p. 40). Qui plus est, l'umbiganda était jugée par la population comme une activité obscène, brutale et violente, ce qui amplifia la nécessité de la pratiquer de la manière la plus discrète qui soit. Au fil du temps, on abandonna ce terme et ses racines africaines au profit de Samba de roda. La roda (" cercle») était constituée de personnes effectuant les chœurs. Au centre de celle-ci figurait un soliste qui chantait et dansait. Avec l'apparition du disque et son succès, l'improvisation, si chère à la samba-de-roda, disparut. «C'est donc le disque qui fait disparaitre l'improvisation et crée la notion d'auteur, arrachant la samba au folklore anonyme et à la transmission orale » (Galvão 2005, p. 124).

Le développement de la samba connut un essor considérable avec la création, par le gouvernement brésilien, de la première station de radio du pays en 1923. "Pour répondre à la demande, elle diffusait la musique la plus populaire de l'époque. L’ère de la samba était arrivée » (Guillermoprieto 1992, p. 37).

\section{L'APPARITION DES ÉCOLES DE SAMBA}

Compte tenu du succès grandissant de la musique samba, il n'était pas envisageable qu'elle ne prenne pas également les traits d'une danse. Comme l'exprime Gilbert Rouget : «Danser c'est inscrire la musique dans l'espace » (Rouget 1980, p. 179). En 1928, la première école de samba voit le jour. « Tous les témoignages s'accordent pour reconnaître à Deixa Falar ${ }^{3}$ le titre de première école de samba » (Galvão 2005, p. 37). La samba s'apparente alors au maxixe, une danse de salon qui se pratique à deux. Son rythme est lent et, par conséquent, ses mouvements sont chaloupés et cadencés. Mais un problème subsistait toujours dans la pratique de la samba : l'héritage de sa réputation décadente issue de l'ère coloniale que l'on retrouvait dans le maxixe. "Le maxixe était attaché d'une réputation d'indécence et les écoles de samba, soucieuses de leur respectabilité naissante, préféraient donc l'éviter " (Galvão 2005, p. 34). Il était alors impératif de créer une autre samba, que ce soit dans les domaines de la musique ou de la danse. Cette nouvelle conception aboutit à une accélération du rythme et, par conséquent, à une intensification du son, ce que rappelle Rouget : "Comme il est fréquent pour toute musique, l'accélération du tempo va le plus souvent de pair avec l'intensification du son » (Rouget 1980, p. 129). 
Une des nombreuses anecdotes de la samba, qui s'ajoute à ses aspects mythologiques, est que le terme d'école de samba, attribué à Ismaël Silva ${ }^{4}$, repose sur un quiproquo. Les sambistas ${ }^{5}$ répétaient à cette époque dans un local vide situé aux abords d'une Université d'enseignement. Des personnes croisaient régulièrement les sambistas et s'étonnaient de les voir sortir de l'Université. Ils ont alors commencé à dire : «c'est d'ici que les professeurs viennent » (Guillermoprieto 1992, p. 38), persuadés qu'ils sortaient de ladite institution. Ce serait ainsi qu'aurait émergé «l'idée d'une école de samba ». Les sambistas regroupaient la batuque ${ }^{6}$, les cordoés 7 et des danseurs. Les arts de rue de l'époque étaient donc réunis dans un même lieu qui connaissait une attention considérable de la part $\mathrm{du}$ peuple en regroupant musique, danse et culture africaine. De nombreuses écoles de samba sont alors créées dans différents quartiers de Rio. En plus d'être un symbole de l'identité noire, les écoles de samba incarnaient l'identité d'un quartier tout entier, lequel pouvait réunir plus de deux mille personnes.

\section{Écoles de SAMba et CARnaval}

Durant l'année 1933, Gétulio Vargas, alors Président du Brésil, dans sa démarche d'appropriation nationale des cultures populaires, qualifie la samba de " musique officielle du Brésil ». Suite à cette reconnaissance, la samba se développe de manière considérable, au point même de devenir indissociable du carnaval. Il faut dire que la présence du carnaval au Brésil remonte à près de quatre siècles, c'est-à-dire « aux premiers temps de la colonisation portugaise, il est cité dans des documents de 1605 sous le nom qu'il portait au Portugal, celui d'entrudo » (Queiroz 1992, p. 11), ce terme signifiant «l'entrée » dans la période du carême. C'est en 1935 que la mairie de Rio rend officielle le concours des écoles de samba (Galvão 2005, p. 43). La manière de jouer et de danser la samba est alors bien différente du maxixe. Les écoles pratiquent la samba-enredo, un style de danse attribué aux sambistas do estàcio, nom provenant du quartier de Rio Estàcio de Sà où le groupe se réunissait pour répéter. La samba-enredo est plus adaptée au défilé : c'est une marche chorégraphiée qui permet la cohésion du groupe. "Si la samba-enredo est associée au défilé des écoles de samba, l'autre genre musical propre au Carnaval, la marchinha, est lié à la danse à la fois individuelle et collective » (Galvão 2005, p. 155). La marchinha est une manière de danser plus adaptée à la rue.

L'idée du concours des écoles de samba était simple : elles « défileraient au Carnaval, et passeraient devant un jury, nommé par le journal Mundo sportivo, qui les évaluerait et leur attribuerait des notes " (Galvão 2005, p. 39). Les écoles de samba adoptent alors deux tendances :

- La première est de s'ouvrir le plus possible à la population afin de posséder le plus grand nombre de participants au défilé. De cette manière, elles peuvent exercer un pouvoir de séduction plus important auprès

4 Ismaël Silva est l'un des premiers professeurs de samba de Rio.

5 Nom donné aux danseurs de samba.

6 Groupe de percussionnistes.

7 Petits groupes de danseurs et musiciens qui paradent dans les rues. Ils sont souvent considérés comme les ancêtres des écoles de samba. 
des membres du jury (qui, dans la majorité des cas, faisaient parti de la classe dominante). «Les écoles de samba n'ont pas pour but de se transformer en une institution fermée mais de 'séduire' le plus grand nombre de personnes, surtout de la classe moyenne " (Matta 1983, p. 133).

- La seconde est de conserver et de renforcer l'identité du quartier que l'école de samba représente. Dans cette conception, elles se referment sur elles-mêmes puisque, pour faire partie d'une école, il faut être membre du quartier qui lui est associé. Ce sont alors « des associations de spectacle fermées, avec une conscience aiguë de l'appartenance de quartier, de groupe et de couleur» (Matta 1983, p. 161).

\section{DE L'IMPORTANCE DU DÉFILÉ DES ÉCOLES DE SAMBA ET LES NOU- VEAUX ENJEUX DU CARNAVAL}

Entre 1935 et 1940, les écoles de samba se construisent et ne ressemblent en rien à l'aspect qu'elles ont aujourd'hui. Chaque école choisit ses couleurs, tout d'abord afin de se différencier lors du passage devant le jury, mais également pour renforcer l'identité et la cohésion du groupe. Ainsi, durant le Carnaval, on reconnait l'école de samba de son quartier en fonction des couleurs qu'elle arbore. De même, les costumes d'aujourd'hui ne peuvent plus être comparés à ceux de l'époque ; les premiers protagonistes des écoles de samba portaient des vêtements plus proches de l'uniforme que du costume. "Durant les premières années, les défilés d'écoles de samba ne ressemblaient en rien à ceux d'aujourd'hui : il n'existait pas de thème unificateur ou d'histoire' à représenter ; il n'y avait pas non plus de chars-allégoriques ; et l'on ne se préoccupait guère des couleurs et des costumes" (Sandroni 2005, p. 99). Par exemple, les batérias (groupe de musiciens) des écoles de samba étaient composées d'un nombre beaucoup plus restreint de percussionnistes qu'à l'heure actuelle. De plus, il n'y avait pas de micro ni d'enceinte lors du passage devant le jury ; la batéria devait donc atténuer le son des percussions afin que les évaluateurs puissent distinguer les prouesses du soliste.

Les années 1940 à 1950 vont contribuer à la création de l'identité des écoles de samba. En effet, l'implication de la classe moyenne sera de plus en plus importante dans les écoles. Le courant esthétique va ainsi se modifier, notamment par les costumes qui feront désormais l'objet d'importants enjeux économiques, mais également par l'investissement sans précédent de la population en terme de temps et d'argent, ainsi que par les retombées publicitaires et économiques que représente le fait de gagner le concours.

Au cours de la décennie suivante, dans les années 1960, «le choix d'un thème pour le défilé des écoles a marqué une nouvelle évolution de la samba " (Sandroni 2005, p. 101). Le thème du Carnaval est souvent choisi parmi des sujets historiques. Le côté spectaculaire se développe et, à partir des années 1980, «les écoles se transforment ouvertement en véritables entreprises, au grand dam des puristes » (Galvão 2005, p. 54). Le Carnaval et le défilé des écoles de samba vont alors être médiatisés par le biais de la télévision, d'abord au niveau national, puis au niveau international. Ce phénomène, qui contribuera à l'expansion de la forme spectaculaire de cette fête, est à l'origine de la désignation du 
Brésil comme "pays du carnaval» (Queiroz 1992, p. 12). Cette déclaration renvoie inévitablement à l'une des thèses de Guy Debord : "Le spectacle n'est pas un ensemble d'images, mais un rapport social entre des personnes médiatisé par des images » (Debord 1996, p. 16). C'est alors qu'en 1984, Oscar Niemeyer ${ }^{8}$ construit le Sambodrômo - édifice d'une longueur de sept cents mètres et d'une capacité de quatre-vingt dix mille personnes édifié exclusivement pour le défilé des écoles de samba, même s'il sert aussi aujourd'hui de complexe pour d'autres événements. Il se compose d'une avenue (avenida Marquês de Sapucai) bordée de gradins, architecture qui rappelle les origines du défilé et, plus généralement, du Carnaval : la rue. Les écoles de samba, dont les batérias se composent aujourd'hui de trois à cinq mille musiciens et danseurs, ont quatrevingt minutes pour traverser l'avenue. Ainsi, l'élément principal qui a permis le développement de la musique samba est la juxtaposition de la musique et de la danse, puisque «danser une musique c'est bien en effet la percevoir d'une manière particulière. C'est remettre le message sous forme de mouvement et non plus le recevoir. On voudrait dire que c'est 'l'agir' et non plus seulement le subir » (Rouget 1980, p. 140).

Or c'est cette succession de phénomènes décrits précédemment qui a contribué à la démesure actuelle du Carnaval de Rio de Janeiro. Son succès ne tient-il pas « au fait que c'est l'ensemble de la société qui profite chaque année, de cette possibilité de mise en scène : dénonciation du racisme, recherche des origines, présentation collective d'identité, exaltation des particularismes culturels " (Agier 2000, p. 7) ? Son inscription dans la société en tant qu'événement cyclique a poussé les écoles de samba à être chaque année plus inventive pour faire que le nouveau défilé se distingue de celui de l'année précédente et pour continuer à séduire les spectateurs. "Toujours différent il est chaque année réinventé » (Agier 2000, p. 9). Cet événement regroupe aujourd'hui des millions d'individus, autochtones ou touristes, venus participer à la fête. Les enjeux économiques relatifs au carnaval sont colossaux et rappellent la prédominance de la société capitaliste et la spectacularisation du monde. C'est donc peut-être en ce sens que « la persistance de la fête (du Carnaval) dans l'univers sauvage du capitalisme sert, avec la petite dose de tradition nécessaire, à l'humanisation de la modernité » (Machado da Silva 1999, p. 96).

\section{RÉFÉRENCES}

Agier, Michel. 200o. Anthropologie du carnaval. La ville, la fête et l'Afrique à Bahia. Marseille : Éd. Parenthèses/IRD.

Debord, Guy. 1996. La société du spectacle. Paris : Gallimard.

Dreyfus, Dominique (dir.). 2005. Musique populaire brésilienne. Paris : Cité de la musique.

Galvão, Walnice Nogueira. 2000. Le Carnaval de Rio. Trois regards sur une fête brésilienne, trad. par Ariane Witkowski. Paris : Éd. Chandeigne.

Guillermoprieto, Alma. 1992. Samba. Une année dans les favelas de Rio de Janeiro. Paris : Plon. 
McGowan, Chris et Ricardo Pessanha. 1999. Le son du Brésil. Samba, bossanova et musique populaire brésilienne, trad. par Emmanuel Baecque. Paris : Éd. Lusophone.

Machado da Silva, Jurémir. 1999. Le Brésil pays du présent. Paris : Desclée de Brouwer.

Matta, Roberto da. 1983. Carnavals, bandits et héros. Ambiguïtés de la société brésilienne, trad. par Danielle Birck. Paris : Seuil. 1 ère éd. 1978.

Queiroz, Maria Isaura Pereira de. 1992. Carnaval brésilien. Le vécu et le mythe. Paris : Gallimard.

Rouget, Gilbert. 1980. La musique et la transe. Esquisse d'une théorie générale des relations de la musique et de la possession. Paris : Gallimard.

\title{
RÉSUMÉ
}

À travers une perspective historique, il s'agit de synthétiser les théories relatives à l'une des musiques et des danses les plus représentatives de la culture brésilienne : la samba. Nous y trouverons des réflexions sur l'un de ses mythes d'origine ainsi que sur la création des écoles de samba et leur imbrication progressive dans le carnaval et dans le cœur du Brésil.

\begin{abstract}
Through a historical perspective, this article aims toward a synthesis of theories relating to a genre of music and dance that is one of the most representative of Brazilian culture: samba. The reader will find reflections about one of the myths of samba's origin as well as about the creation of the samba schools and their gradual introduction into the Carnival and into the heart of Brazil.
\end{abstract}

